\title{
GEOLOGÍA
}

\section{PALEOSUELOS DEL MIOCENO EN EL DESIERTO DE LA TATACOA}

\author{
María T. Flórez M.*, Luis N. Parra S.**, Daniel F. Jaramillo J.*** y José M. Jaramillo M.****
}

\section{RESUMEN}

Flórez M. M. T., L.N. Parra S., D. F. Jaramillo J., J. M. Jaramillo M.: Paleosuelos del mioceno en el desierto de la tatacoa. Rev. Acad. Colomb. Cienc. 37 (143): 229-244, 2013. ISSN 0370-3908.

\begin{abstract}
Al interior de las dos secuencias de "capas rojas" de Fields (1959), se reconocieron siete fragmentos de paleosuelos, formados en el Mioceno, bajo climas contrastados hasta áridos, y en paleorelieves colinados de baja altitud. Estos paleosuelos fueron portadores de biomas secos y debieron coexistir con planicies aluviales pobladas por biomas húmedos boscosos dependientes en gran medida de la humedad residual del sedimento y tolerantes a la inmersión temporal durante las inundaciones de grandes ríos.
\end{abstract}

Palabras clave: Estratigrafía, capas rojas, suelos relictos, cambio climático en el pasado, Colombia.

\begin{abstract}
Within the two sequences of "red beds" of Fields (1959) were recognized seven fragmentary paleosols formed in the Miocene under contrasted to arid climates and hills of low altitude. When formed these paleosols were covered by dry biomes and they laterally coexisted with floodplains populated by trees tolerant to residual moisture on the sediment and temporary floods of great rivers.
\end{abstract}

Key words: Stratigraphy, red beds, relict soils, climatic change in the past, Colombia.

\section{Antecedentes}

Históricamente los fósiles han sido la principal motivación para estudiar las rocas que afloran en el desierto de la Tatacoa (Stille, 1907, 1938; Royo y Gómez 1942; Fields, 1959;
Stirton, 1953; Van Houten and Travis, 1958; Welman, 1970; Takemura, 1986; Guerrero, 1991, 1993; Villarroel et al., 1996). En la Plancha Geológica de Colombia $\mathrm{N}^{\circ}$ 303 (Ingeominas, 2002), la zona está cubierta por rocas sedimentarias clásticas de ambientes fluviales y lagunares del

* PhD. MSc. Inga Geóloga. Profesor Titular. Universidad de Antioquia. Medellín. E-mail: mariateresa.florez@gmail.com

** PhD. MSc. Ing Geólogo. Profesor Asociado. Universidad Nacional de Colombia. Medellín. E-mail: Inparra@gmail.com

*** MSc. Ing Agrónomo. Profesor Titular. Universidad Nacional de Colombia. Medellín. E-mail: dfjaramillo@gmail.com

**** PhD. MSc. Ing. Geólogo. Investigador Gmas ${ }^{+}$. E-mail: gmas@gmaslab.com 
Mioceno Superior, correspondientes estratigráficamente al Grupo Honda e incluye rocas siliciclásticas finas y medias de coloraciones grises y verdosas (arenas, limos y arcillas) y, en menor medida conglomerados arenosos y areniscas conglomeráticas. De particular interés son tres conjuntos de capas rojizas, de diferentes edades, que fueron nominadas como "Upper red beds", "Lower red beds" y "Ferruginous sands" y cartografiadas en detalle por Fields y Henao, 1949 (Figura 1); estas capas rojas afloran en la vereda el Cuzco del desierto de la Tatacoa, están separadas entre sí por estratos de coloraciones grises y han sido analizadas por Fields, 1959.

Los estratos rojizos han llamado la atención de muchos investigadores que han propuesto diferentes ideas para explicar el origen de esa coloración: 1) Litocromía o color original producto de la depositación de clastos y/o matrices coloreadas, 2) Alteración del sedimento original atribuible a la diagénesis temprana, y 3 ) Coloración producida por pedogénesis en condiciones superficiales.

El concepto de inercia edafogenética, introducido por Bryan y Teakle, 1949, postula que ciertas propiedades del suelo tienden a persistir incluso millones de años después de que los factores responsables de su formación han dejado de actuar, mientras que otras tienen una duración más limitada (Yaalon, 1971). Este concepto es la base para interpretar los rasgos de los paleosuelos e inferir las condiciones ambientales bajo las cuales se formaron en el pasado y sustenta el objetivo específico de este trabajo, el cual trata de reconstruir la edafogénesis de los paleosuelos presentes en la vereda el Cuzco, desarrollados a partir de rocas sedimentarias clásticas de ambientes fluviales y lagunares correspondientes a la sección superior del Grupo Honda, utilizando para ello datos morfológicos, químicos y mineralógicos que han persistido en esos paleosuelos.

\section{Marco teórico y Estado del arte}

El término paleosuelo se aplica a un suelo que se ha formado en un paisaje del pasado, bajo condiciones, principalmente climáticas distintas, con el consiguiente cambio de vegetación (Ruhe, 1956, 1965; Yaalon, 1971 y Catt, 1991). Esta definición incluye no sólo a los suelos enterrados o fósiles, sino también a los suelos relictos que comenzaron su desarrollo bajo condiciones distintas a las actuales, pero que todavía continúan evolucionando hoy en día. Los paleosuelos durante su formación han requerido de un período de estabilidad geomorfológica, de no sepultamiento ni erosión, al menos de una manera significativa, y en escala de pocas centurias a milenios. Estos materiales son excelentes indicadores de los biomas del pasado, ya que son especialmente sensibles a la temperatura y precipitación, al tipo de vegetación y a las condiciones de drenaje que existían en la época de su formación (Morrison, 1978). Los criterios para el estudio y diferenciación de los paleosuelos de otros materiales similares han evolucionado significativamente en los tiempos modernos (Retallack, 1988, 2001; Kraus, 1999; Nettleton et al., 2000).

Los paleosuelos han sido objeto de trabajo en varios países, p.e., Gey y García (1993) estudiaron un perfil de meteorización edáfico sobre filitas que se encuentra enterrado bajo los sedimentos de la cuenca Terciaria de As Pontes de García (Noreste de España). El análisis mineralógico y los rasgos micromorfológicos (esferosideritas) ponen de manifiesto que el suelo se desarrolló bajo dos paleoambientes sucesivos: el inicial, bajo condiciones sub-aéreas, que condujo a la formación de caolinita y goethita, y el segundo, con hidromorfismo permanente afectó fundamentalmente a los compuestos de hierro, originándose siderita.

Potenciano et al., (1997) reportan la presencia de paleosuelos rojos en la cuenca Terciaria del rio Amargillo (Toledo), los cuales muestran un buen desarrollo de horizontes cálcicos y argílicos que podrían corresponder a Alfisoles, los cuales pudieron haberse desarrollado bajo un clima semiárido bastante contrastado entre una estación húmeda y seca que se registró en el mediterráneo y en el sub-trópico. Los índices de paleoalteración química evidencian el fuerte lavado de carbonatos y otras sales y la acumulación de Fe y Ti.

Fernández et al., (1998) realizaron un análisis mineralógico y micromorfológico en la zona de confluencia de las partes distales de los sistemas de abanicos aluviales miocenos de Somosierra-Ayllón al Sureste y de Honrubia al Noroeste de España. Los depósitos procedentes de Honrubia se caracterizan por los frecuentes episodios de encostramiento, con presencia de esmectita o de palygorskita. Los depósitos de Somosierra-Ayllón se diferencian por su color más rojizo, por la ausencia de encostramientos carbonatados y por estar menos afectados por las alteraciones edáficas debido a interrupciones prolongadas en la sedimentación. Las características sedimentológicas y paleontológicas indican un clima cálido dominado por estaciones secas (Araenteros (1986), citado por Fernández et al., 1998).

Retallack y kyrbi (2007) reportan la presencia de paleosuelos del Mioceno medio en la Formación Cucaracha de Panamá, con abundante pirita y rizolitos, similares a los suelos de manglares intermareales de la Florida, Estados Unidos (Altschuler et al., 1983). En la misma formación unos paleosuelos son grises, como los de los pantanos de agua dulce, y otros, con mejor drenaje, son de color rojo, oxidados, tienen aureolas monótonas de rizolitos y carbonatos indicativos de una vegetación de alta productividad que permitió su desa- 
rrollo. Estos autores indican la presencia de nódulos de barita (esferulas que recuerdan a las rosas del desierto) que parecen ser parte del perfil genético. Dichas características llevaron a los autores a plantear que la formación de estos paleosuelos estuvo relacionada con el cambio climático global que se registró durante el Mioceno medio, el cual se caracterizó por una época de dramáticas fluctuaciones climáticas, con un clima más seco y más fresco, y una estación seca menos marcada, con más vegetación abierta de menor estatura. Los paleosuelos panameños estaban en o cerca del nivel del mar. Estos ciclos de calor y humedecimiento también son evidentes en periodos similares en paleosuelos en Oregon, Montana, Nebraska, Alemania, Japón, Kenia, Pakistán y Australia (Retallack, 1991, 2004b, 2007 y Schwarz, 1997).

En Colombia, Pulido et al., (1990) estudiaron remanentes de paleosuelos del Cuaternario en los alrededores de la Sabana de Bogotá y destacan la presencia de suelos relictos formados entre el último interglaciar y el pleniglaciar superior, con edades comprendidas entre 8700 y más de 49000 años $\mathrm{BP}$, cuyos rasgos evidencian la influencia que han tenido los cambios climáticos sobre su naturaleza. Clasifican estos paleosuelos como Cryumbrepts, Cryochrepts, Cryandepts y Paleustalfs, de acuerdo con las condiciones ambientales reinantes en la época de su formación.

González et al., (1993) estudiaron una columna de suelos de $9.87 \mathrm{~m}$ de espesor en el Norte de la cordillera Central colombiana y en ella definieron seis secuencias de paleosuelos desarrollados a partir de tefras, con edades que fluctuaron entre 2500 años BP, la más reciente, y un estimado entre los 55000 y 120000 años BP, para la más antigua. De acuerdo con las propiedades observadas en los paleosuelos identificados se pudieron definir varios cambios ambientales importantes durante el tiempo de formación de los suelos, presentándose climas más húmedos que el actual que originaron horizontes A con gran acumulación de materia orgánica, climas marcadamente estacionales que desarrollaron horizontes argílicos y climas secos que generaron discordancias erosionales con fragmentos de horizontes plácicos mezclados con el horizonte subyacente.

Mantilla et al., (2011) hacen un recuento amplio de otros estudios realizados en paleosuelos de varias regiones de Colombia como la Orinoquia, el Alto Magdalena, el Parque de los Nevados (Tolima y Caldas), la región Caribe y el Occidente de Antioquia. En estos estudios se describen y clasifican paleosuelos en los órdenes Andisol, Oxisol, Ultisol, Alfisol e Inceptisol con edades de hasta 730000 años BP, y se identifican cuatro fases áridas entre el Holoceno medio y el antepenúltimo glacial.

Fields y Henao (1949) delimitaron y cartografiaron tres paquetes de sedimentos rojos cercanos a la quebrada la Venta (departamento del Huila, Colombia), a los que denominaron "ferruginous sands", "lower red beds" y "upper red beds" en orden estratigráfico de base a techo, los cuales están separados entre sí por secuencias normales de limos arcillosos grisáceos (Figura 1).

Fields (1959) explica el mapa elaborado en 1949 y aclara que las "arenas ferruginosas", con un espesor de $13 \mathrm{~m}$, son arcósicas. En las "capas rojas inferiores" resalta su naturaleza lodolítica, de unos $14.5 \mathrm{~m}$ de espesor, y subraya la presencia de nódulos y concreciones calcáreas en superficies alteradas. De las "capas rojas superiores" destaca su espesor de $70 \mathrm{~m}$, su bajo buzamiento, la formación de extensos eriales de color rojo, su naturaleza arcillosa (bentonitas por su expansión en agua), la incorporación de cenizas volcánicas, nódulos calcáreos y de fósiles de vertebrados. Con respecto al color rojo anota que no está presente en todas las capas que conforman esos paquetes de sedimentos y lo atribuye a un pigmento limonítico soluble en $\mathrm{HCl}$ en caliente que al ser eliminado deja un residuo mineral gris, el cual se forma por oxidación sub-aérea de minerales portadores de hierro. Fields (1959) no considera un posible origen pedogenético para estas capas.

Guerrero (1993), refiere para la Tatacoa algunos rasgos pedogenéticos tales como pedotúbulos calcáreos, evidencias de bioturbación, nódulos de calcita, trazas de raíces, nódulos de óxidos de hierro, horizontes rojizos y púrpuras, restos de madera y fósiles de roedores en sus galerías. Sin embargo, estas evidencias de pedogénesis se refieren para todo el grupo Honda y no indica la localización de perfiles específicos.

\section{Materiales y Métodos}

\section{Descripción del área de estudio}

La zona de interés se localiza en el Desierto de La Tatacoa, en el Alto Magdalena, zona rural de los municipios de Baraya y Villavieja en el departamento del Huila, a $3^{\circ} 13^{\prime}$ de Latitud Norte y $75^{\circ} 10^{\prime}$ de Longitud Oeste. La región está vegetada por ecosistemas secos, excepto en los bosques de galería donde persisten algunas especies no tolerantes a la sequía (Universidad Sur Colombiana, USCO, 2006). El desierto tiene una extensión de $330 \mathrm{~km}^{2}$, presenta una erosión hídrica intensa y está cruzado por multitud de caños-cárcavas que están secos durante gran parte del año y que producen grandes arroyadas en los meses de invierno que llegan hasta los cauces principales de los ríos La Vieja, Cabrera, Tatacoa, La Venta, Cerbatana y Villavieja.

De acuerdo con USCO (2005) la zona presenta un clima semiárido ecuatorial, caracterizado por una temperatura anual 
media de $30^{\circ} \mathrm{C}$, con dos periodos lluviosos y dos secos en el año, una humedad relativa promedia de $64 \%$ y brillo solar que se acerca a 5 horas/día. Los vientos son muy débiles o inexistentes. El aire seco descendente y las estables condiciones atmosféricas son la causa de la existencia del clima semiárido en el Desierto de La Tatacoa.

En consonancia con las condiciones climáticas, el modelamiento del paisaje del área está relacionado con eventos de desecamiento, concentración intensa de la escorrentía en torrentes de gran poder erosivo durante los aguaceros intensos y posterior erosión de la capa superficial con la consiguiente formación de caños, grandes cárcavas de hasta $30 \mathrm{~m}$ de profundidad, pilares erosivos y otras geoformas típicas de esta condición climática. A la severidad de los procesos erosivos han contribuido la prolongada actividad ganadera en el área y la deforestación.

El Desierto La Tatacoa pertenece a las zonas de vida de bosque seco tropical (bs-T) y bosque muy seco tropical (bmsT), las cuales corresponden a las provincias de humedad denominadas subhúmeda y semiárida, respectivamente. Las áreas pertenecientes al bs-T poseen una precipitación total anual que apenas supera los $1000 \mathrm{~mm}$ y una biotemperatura que alcanza a sobrepasar $\operatorname{los} 28^{\circ} \mathrm{C}$, mientras que las áreas de bms-T, aunque también pueden tener la biotemperatura mencionada, posee una precipitación total anual ligeramente inferior a los $1000 \mathrm{~mm}$. Con estas características, es muy probable la presencia de una asociación edáfica seca, cuyos periodos de agua disponible en el suelo son más cortos y los de déficit de humedad más largos, situación que se agrava durante los años en que se presenta la fase cálida del fenómeno de El Niño-Oscilación del Sur.

Aunque la temperatura media ambiental es de $30^{\circ} \mathrm{C}$, durante los días de los meses más secos, entre el mediodía y primeras horas de la tarde, la temperatura ambiental puede sobrepasar los $40^{\circ} \mathrm{C}$, lo que tiende a inhibir temporalmente varias funciones fundamentales de las plantas. La eco-región presenta una gran importancia para la preservación de la diversidad de especies adaptadas a la sequía en formaciones de matorral espinoso, cardonales y algunas formaciones transicionales hacia selvas perennifolias y caducifolias estacionales.

En gran parte de la superficie del Desierto de La Tatacoa, los suelos actuales han sido erosionados y reemplazados por

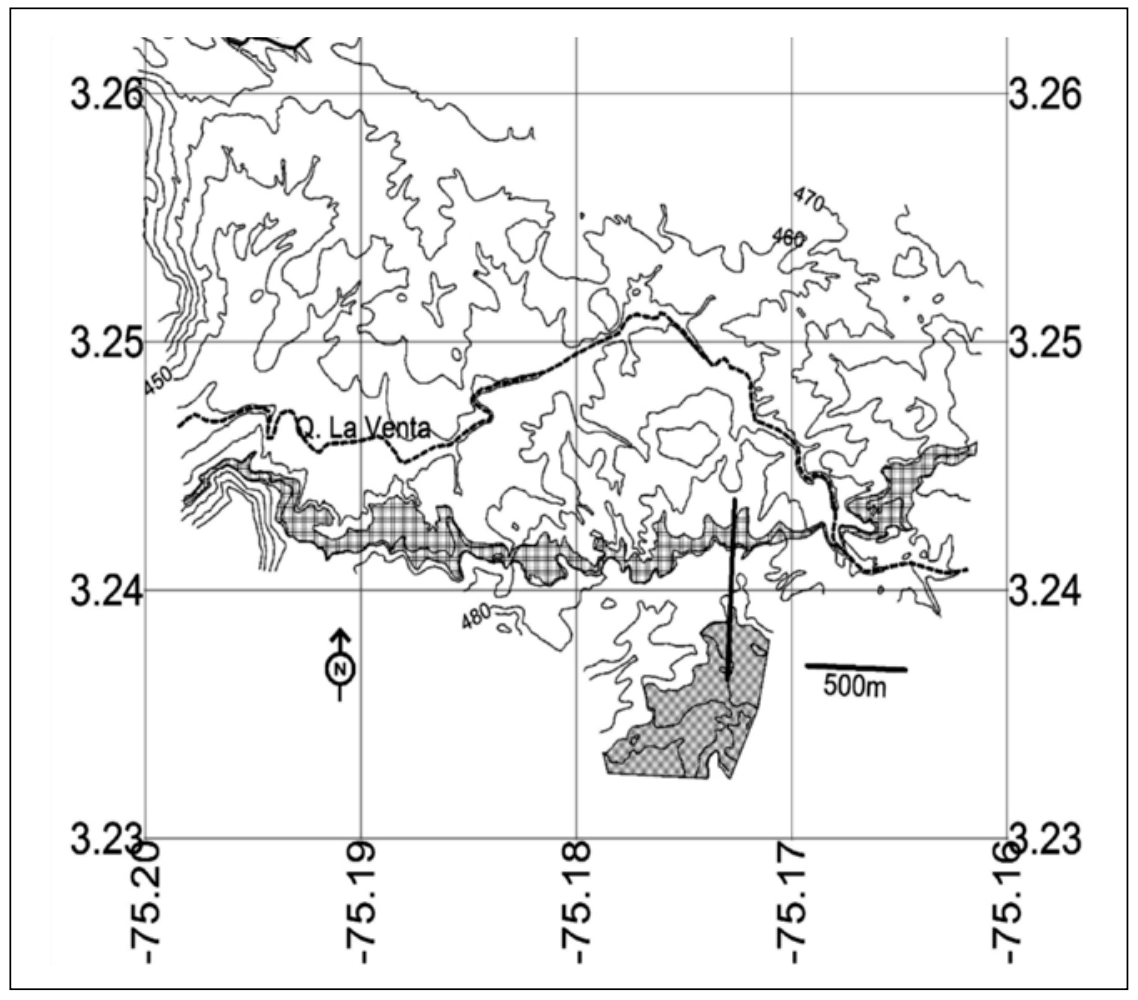

Figura 1. Mapa digitalizado de Fields y Henao (1949). La línea vertical indica el transecto donde se efectuó el levantamiento de los paleosuelos. Punteado fino es la arenisca

ferruginosa, en cuadrados horizontales los paleosuelos inferiores y en diagonal los superiores. 
afloramientos rocosos. El color de los suelos es de tonalidad clara, parda, rojiza y amarillenta, aunque existen áreas de colores grises oscuros, en zonas de cultivo, debido a la presencia de materia orgánica. La granulometría está conformada por partículas de arena, limos y arcilla en las partes bajas, y por fragmentos de roca en lomas y colinas. Los suelos son porosos en superficie, poco profundos. Es frecuente la presencia de sales en ellos, lo que reduce su nivel de fertilidad y su productividad natural. Las propiedades anteriores, junto con la limitación severa en el suministro de agua hacen que estas tierras se clasifiquen en la Clase Agrológica VIII.

\section{Localización del sitio experimental}

El levantamiento de los suelos y paleosuelos se realizó sobre un transecto en la Vereda el Cuzco del municipio de Villavieja, Desierto de La Tatacoa, departamento del Huila, Colombia, en el sitio conocido como "El Observatorio". Allí se describieron tres secciones verticales y continuas de sedimentos que incluyeron el suelo actual y siete paleosuelos que forman parte de lo que denominó Fields (1959) como "capas rojas" (Figura 1).

\section{Trabajo de campo}

En campo se describieron los perfiles de los suelos según el protocolo establecido por Schoeneberger et al., (2002), complementándola con las guías y procedimientos seguidos para los paleosuelos por Retallack (1988, 2001), Kraus (1999) y Nettleton et al., (2000). Se realizaron observaciones relacionadas con la localización, fisiografía, elevación y pendiente del paisaje circundante. Se observó la condición de drenaje, la pedregosidad, la erosión y la localización del manto freático. Se identificaron los horizontes de los perfiles de suelos y paleosuelos y se identificaron las capas sedimentarias localizadas entre ellos, definiendo su profundidad, espesor, color y textura. Este protocolo fue completado con la toma de muestras (disturbadas) de suelos y paleosuelos para su descripción detallada y posterior análisis de laboratorio. Los clases de suelos y paleosuelos fueron clasificados a nivel de subgrupo según el Sistema Taxonómico de Clasificación de Suelos del USDA (Soil Survey Staff, SSS, 2010). Se tomaron fotografías y se realizaron los diagramas estratigráficos respectivos de todo lo descrito.

\section{Propiedades evaluadas en laboratorio}

Las muestras de suelo colectadas en el campo se llevaron al Laboratorio de Suelos de la Universidad Nacional de Colombia para los respectivos análisis de caracterización. Se secaron en un horno durante 24 horas a $35^{\circ} \mathrm{C}$, se disgregaron con rodillo de madera y se pasaron por un tamiz de 2 $\mathrm{mm}$. Con las muestras secas y tamizadas se midió el pH con un potenciómetro en una relación suelo y agua de 1:1; el contenido de bases intercambiables ( $\mathrm{Ca}, \mathrm{Mg}, \mathrm{K}$ y $\mathrm{Na}$ ) y la capacidad de intercambio catiónico (CIC), mediante extracción con acetato de amonio $1 \mathrm{M}(\mathrm{pH} 7)$ y cuantificación por absorción atómica, todos expresados en $\mathrm{cmol}(+) / \mathrm{kgsuelo}$. El contenido de materia orgánica (MO) se determinó por oxidación con dicromato de potasio y ácido sulfúrico (método de Walkley-Black). La capacidad de intercambio catiónico efectiva (CICE) se determinó por la suma de bases extraídas con acetato de amonio normal y neutro, más la acidez intercambiable extraída con $\mathrm{KCl}$. El contenido de $\mathrm{Fe}, \mathrm{Mn}$, $\mathrm{Cu}$ y $\mathrm{Zn}$ se determinó por el método de Olsen modificado. El fósforo disponible (P) se determinó por el método Bray II. Todos los elementos menores y el $\mathrm{P}$ se cuantificaron en $\mathrm{mg} / \mathrm{kg}$ suelo.

La caracterización mineralógica de los suelos y paleosuelos muestreados se realizó en el Laboratorio GMAS ${ }^{(+)}$, mediante difracción de rayos $\mathrm{X}$ con un Difractómetro de Rayos $\mathrm{X}$ Bruker D8 Advance Serie I, tanto en la fracción arcilla como en un preparado en polvo impalpable del suelo total. A la fracción arcilla se le aplicaron los tratamientos de glicolado y calentado, obteniéndose tres resultados por muestra (muestra secada al aire, muestra calentada a $550^{\circ} \mathrm{C}$ y muestra tratada con Ethylen glicol).

\section{Resultados}

En el sitio de interés se levantaron el suelo actual y dos secuencias de paleosuelos nombradas como Secuencia de Paleosuelos Superior y Secuencia de Paleosuelos Inferior las cuales están separadas por un intervalo de sedimentos normales limos y arenas grises, dichos paleosuelos se corresponden con las secuencias "Upper red beds" y "Lower red beds" respectivamente tal como aparecen en el mapa de Fields y Henao (1949). En este artículo se describen detalladamente los paleosuelos y el suelo actual pero no se hace énfasis en la secuencia de sedimentos intercalados. Toda la estratigrafía descrita para este artículo comprende un espesor de $94.85 \mathrm{~m}$.

\section{Caracterización química del suelo actual y de los paleo- suelos}

\section{El suelo actual}

El suelo actual está formado por dos horizontes identificados como A y Bt (Foto 1), los cuales se describen a continuación. En la Tabla 1, se presentan los resultados de la evaluación de las propiedades químicas de este suelo y en la Tabla 2, la composición mineralógica de la fracción arcilla del horizon- 




Foto 1. Suelo actual en la zona del Cuzco, Desierto de la Tatacoa.

A $\quad 0-36 \mathrm{~cm}$ ( $0.36 \mathrm{~m}$ de espesor); color en húmedo 7.5YR4/4 (pardo oscuro); franco arcilloso; estructura en bloques subangulares medios, débiles; ligeramente plástico, ligeramente pegajoso; muchos poros finos; abundantes raíces finas y medias; límite inferior claro, plano.

Bt $36-65 \mathrm{~cm}$ (0.29 $\mathrm{m}$ de espesor); color en húmedo 5YR4/6 (rojo amarillento); franco arcilloso a arcilloso; estructura en bloques subangulares medios, fuertes; ligeramente plástico, ligeramente pegajoso; muchos poros finos; comunes pedotúbulos; muchos argílanes continuos, prominentes; comunes nódulos de hasta 5 cm de diámetro de color 10YR7/2 (gris claro); muchas raíces finas y medias; límites claros. te argílico que posee. En la Figura 2 se presenta el difractograma obtenido para los minerales y las arcillas presentes en el suelo.

Según los resultados de la Tabla 1, este suelo es ligera a moderadamente alcalino, presenta muy bajo contenido de $\mathrm{MO}$, tiene una textura pesada, alto contenido de bases, alta CIC, no tiene problemas de saturación con $\mathrm{Na}$, superficialmente tiene bajo contenido de $\mathrm{P}$ pero en profundidad se encuentra bien abastecido con este elemento y presenta bajos contenidos de elementos menores. No se reportan contenidos de $\mathrm{Mn}$ y $\mathrm{Zn}$ porque estuvieron en cantidades no detectables en el laboratorio. Las características apuntadas muestran un suelo con un nivel de fertilidad adecuado, excepto por el contenido orgánico.

Las propiedades que presenta este suelo se derivan de las condiciones ambientales en las que ha evolucionado. El clima cálido seco en que se encuentra ha generado una mineralización intensa de la MO, ya que el ambiente es netamente oxidante y productor de escasa biomasa vegetal. También ha permitido la acumulación de las bases liberadas de los minerales primarios por la meteorización, debido a que la lixiviación es un proceso que no ha actuado eficientemente por la falta de agua.

El pH alto es consecuencia de la acumulación de bases y de la poca acumulación de materia orgánica. Los colores rojizos también se relacionan con el ambiente que ha oxidado intensamente los compuestos de Fe, a pesar de que este elemento no es muy abundante (no se requiere cantidades altas para que él se manifieste).

La erosión hídrica severa que se presenta se debe también a la condición seca del clima. La sequía prolongada hace que la vegetación protectora del suelo tenga una baja cobertura de éste, de modo que al llegar las primeras lluvias el suelo está descubierto y recibe el impacto directo de las gotas de agua que lo disgregan y lo sellan superficialmente, generándose la escorrentía que arrastra las partículas sueltas ocasionando la erosión observada.

Tabla 1. Propiedades* químicas del suelo actual en el área de trabajo.

\begin{tabular}{|c|c|c|c|c|c|c|c|c|c|c|c|c|c|c|c|c|c|c|}
\hline \multirow{2}{*}{ Horizonte } & \multicolumn{4}{|c|}{$\%$} & \multirow{2}{*}{ pH } & \multicolumn{6}{|c|}{$\mathrm{cmol}(+) / \mathrm{kg}$ suelo } & \multicolumn{2}{|c|}{$\%$} & \multicolumn{5}{|c|}{$\mathrm{mg} / \mathrm{kg}$ suelo } \\
\hline & $\mathbf{A}$ & $\mathbf{L}$ & $\mathbf{A r}$ & MO & & $\mathrm{Ca}$ & $\mathrm{Mg}$ & $\mathbf{K}$ & $\mathbf{N a}$ & CIC & CICE & SB & PSI & $\mathbf{P}$ & $\mathbf{S}$ & $\mathbf{F e}$ & $\mathbf{C u}$ & B \\
\hline A & 28 & 34 & 38 & 0,02 & 7,5 & 14,7 & 4,12 & 0,13 & 0,69 & 29,4 & 19,6 & 66,9 & 2,35 & 15 & 6 & 1 & 0,2 & 1,6 \\
\hline $\mathrm{Bt}$ & 22 & 38 & 40 & 0,04 & 8,3 & 17,7 & 4,53 & 0,12 & 1,11 & 31,4 & 23,5 & 74,7 & 3,53 & 70 & 5 & 0,3 & 0,2 & 0,4 \\
\hline
\end{tabular}

* A, L, Ar: Contenidos de arena, limo y arcilla, respectivamente. MO: contenido de materia orgánica. CIC: CIC medida a pH 7. CICE: CIC efectiva. SB: Saturación de bases. PSI: Porcentaje de sodio intercambiable.

$\mathrm{CICE}=(\mathrm{Ca}+\mathrm{Mg}+\mathrm{K}+\mathrm{Na}) \mathrm{SB}=[(\mathrm{Ca}+\mathrm{Mg}+\mathrm{K}+\mathrm{Na}) / \mathrm{CIC}] * 100 \mathrm{PSI}=(\mathrm{Na} / \mathrm{CIC}) * 100$ 


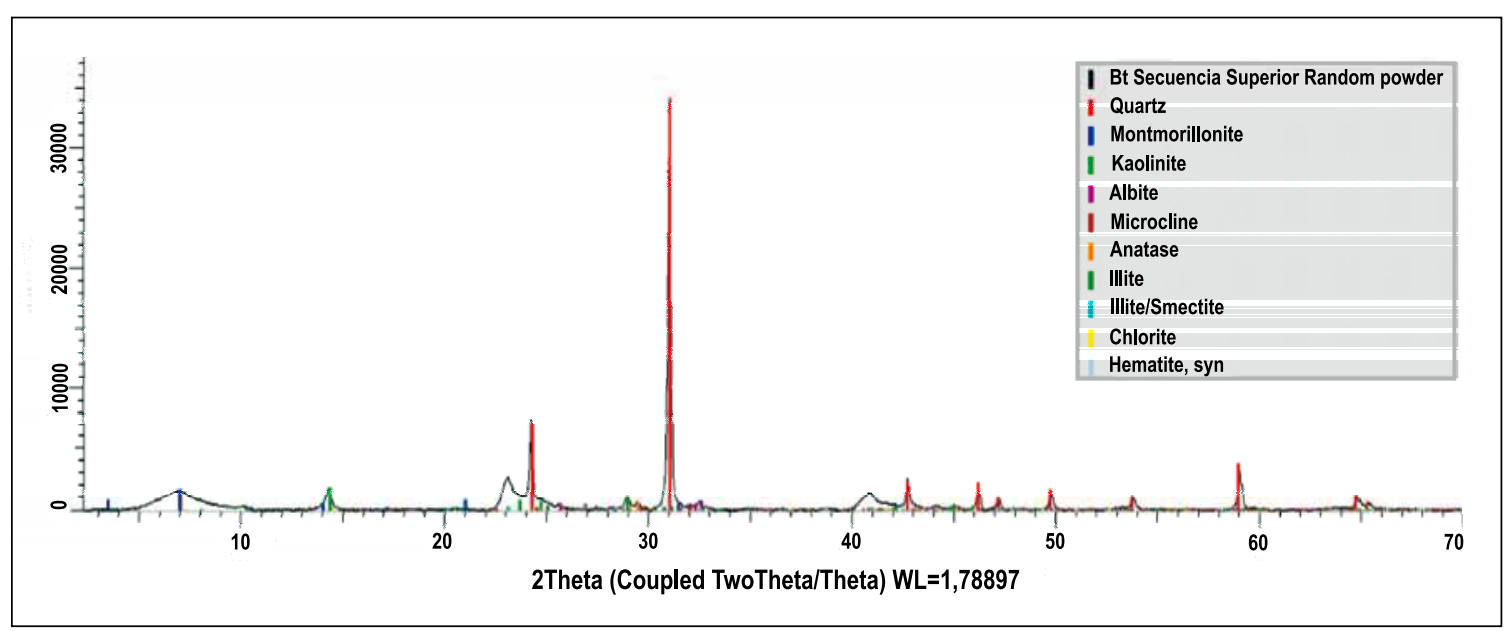

Figura 2. Difractograma de minerales y arcillas presentes en el horizonte Bt del suelo actual en el desierto de La Tatacoa.

Tabla 2. Contenido mineralógico* (\%) del horizonte argílico del suelo actual en el área de trabajo.

\begin{tabular}{|c|c|c|c|c|c|c|c|c|c|}
\hline \multirow{2}{*}{ Horizonte } & \multicolumn{4}{|c|}{ Minerales de arcilla } & \multicolumn{5}{c|}{ Otros minerales } \\
\cline { 2 - 10 } & Illita-mica & I/S & Esmectita & Caolinita & Cuarzo & Fp & PI & Anatasa & Hematita \\
\hline $\mathrm{Bt}$ & 3 & 2 & 17 & 19 & 53 & 1 & 2 & 2 & 1 \\
\hline
\end{tabular}

* I/S: Intergrado Illita-Esmectita. Fp: Feldespato potásico. Pl: Plagioclasa.

La presencia de argílanes evidencia un proceso de iluviación de arcilla, el cual se desarrolla de manera óptima en ambientes donde hay alternancia de condiciones húmedas y secas fuertemente contrastadas (Buol et al., (1997), SSS (1999)). La composición de la arcilla corresponde a las condiciones climáticas mencionadas pues en un clima húmedo la esmectita prácticamente estaría ausente debido a la alta meteorización y lixiviación de bases, lo que aumenta la actividad del Al y propicia la formación de caolinita. Además, los óxidos de hierro están en muy poca cantidad. El alto contenido de cuarzo proviene del material parental.

El suelo actual presenta, como propiedades diagnósticas para su clasificación, un régimen de humedad ústico y de temperatura isohipertérmico, su epipedón es ócrico y tiene un endopedón argílico con saturación de bases mayor a $35 \%$. Estas características ubican el suelo en el orden Alfisol y el suborden Ustalf. Al nivel de gran grupo, los incrementos de arcilla, los colores y la cantidad de argilanes en el horizonte argílico, así como la ausencia de otros horizontes diagnósticos, hacen que el suelo se clasifique como Paleustalf. El tipo de cobertura vegetal dominante en la zona y la severidad de la erosión hídrica presente en ella hacen pensar en que el régimen de humedad del suelo puede acercarse a una condición arídica, lo que define este suelo, al nivel de subgrupo, como Aridic Paleustalf.

\section{Paleosuelos en la Secuencia Superior ("Upper Red Beds" de Fields y Henao, 1949).}

La secuencia tiene un espesor de $16.15 \mathrm{~m}$ y está constituida por capas de arenas y limos de colores pardos en el techo y grises y gris oliva entre los paleosuelos. En ella se encuentran cuatro fragmentos de paleosuelos identificados, desde el techo hacia la base, como $2 \mathrm{AC}-2 \mathrm{C} 1-2 \mathrm{C} 2-2 \mathrm{C} 3-2 \mathrm{C} 4$; $3 \mathrm{~B}$ tnss; $5 \mathrm{Btn} 1-5 \mathrm{~B} \operatorname{tn} 2$ y $7 \mathrm{Btn}$, con espesores promedios de $2.98 \mathrm{~m}, 1.05 \mathrm{~m}, 3.89 \mathrm{~m}$ y $4.82 \mathrm{~m}$, respectivamente (Foto 2 ). Las características dominantes de estos paleosuelos son la coloración roja, con Hues $5 \mathrm{YR}$ y 7,5YR, values y chromas menores que 6 , las texturas arcillosas, el buen desarrollo estructural y la presencia de argilanes, slickensides y horizontes nátricos. En la Tabla 3, se presentan los resultados de los análisis químicos realizados a los paleosuelos encontrados en esta secuencia de materiales y en la Tabla 4 y Figura 3, la composición mineralógica de la fracción arcilla de los horizontes argílicos que posee. La estratigrafía de los materiales encontrados en esta secuencia se presenta a continuación, utilizando la nomenclatura que le correspondería a cada uno en una descripción pedológica.

2AC $\quad 0.650 .91 \mathrm{~m}$ (0.26 m de espesor); paleosuelo de color en húmedo 10YR5/8 (pardo amarillento); franco arenoso; estructura masiva; dura en seco; no plástica, 
no pegajosa; poros finos y medios; límite abrupto y plano.

2C1 $0.91-1.40 \mathrm{~m}$ (0.49 $\mathrm{m}$ de espesor); capa de arenas medias a finas, de color en húmedo 10YR5/6 (pardo amarillento); sin estructura (masiva); dura en seco; no plástica, no pegajosa; muchos poros finos y medios; límites abruptos y planos.

2C2 $1.40-2.00 \mathrm{~m}(0.60 \mathrm{~m}$ de espesor); capa de arenas medias a finas, de color en húmedo 10YR5/8 (pardo amarillento); sin estructura (masiva); dura en seco; no plástica, no pegajosa; muchos poros finos y medios; límites abruptos y planos.

2C3 $2.00-2.33 \mathrm{~m}$ (0.33 $\mathrm{m}$ de espesor); capa de arenas medias a finas, de color en húmedo 10YR5/6 (pardo amarillento); sin estructura (masiva); dura en seco; no plástica, no pegajosa; muchos poros finos y medios; límites abruptos y planos.

2C4 $2.33-3.63 \mathrm{~m}$ (1.30 $\mathrm{m}$ de espesor); capa de arenas medias a finas, de color en húmedo 10YR5/8 (pardo amarillento); sin estructura (masiva); dura en seco; no plástica, no pegajosa; muchos poros finos y medios; límites abruptos y planos.

3Btnss3.63 - $4.68 \mathrm{~m}$ (1.05 $\mathrm{m}$ de espesor); paleosuelo de color en húmedo 5YR4/6 (rojo amarillento); arcilloso; estructura en bloques subangulares medios, fuertes; friable, plástico, ligeramente pegajoso; frecuentes manchas de óxidos de hierro y comunes argílanes continuos, definidos; pocas raíces finas y pocos poros finos. Internamente tiene nódulos arcillosos de hasta $5 \mathrm{~cm}$ de diámetro de color 10YR7/2 (gris claro). Presentes slickensides estriados, bien definidos y grietas verticales. Límites abruptos y planos.

4C1 $4.68-6.34 \mathrm{~m}$ (1.66 $\mathrm{m}$ de espesor); capa de limolita (textura limosa) de color en húmedo 5Y7/2 (gris claro); sin estructura (masiva); muy dura en seco, no plástica, ligeramente pegajosa; muchos poros finos; límites abruptos y planos.

4C2 $6.34-6.70 \mathrm{~m}(0.36 \mathrm{~m}$ de espesor); capa de limolita (textura limosa) de color en húmedo 5Y7/3 (amarillo pálido); sin estructura (masiva); muy dura en seco, no plástica, ligeramente pegajosa; muchos poros finos; límite abrupto y plano.

5Btn1 6.71 - $9.50 \mathrm{~m}$ (2.79 $\mathrm{m}$ de espesor); paleosuelo de color en húmedo 5YR5/6 (rojo amarillento); arcilloso; estructura en bloques subangulares medios, fuertes; plástico, ligeramente pegajoso; muchos argílanes continuos, prominentes; abundantes manchas de óxidos de hierro; pocas raíces finas y pocos poros finos; límites abruptos y planos.

Tabla 3. Propiedades* químicas de los paleosuelos de la secuencia superior en el área de trabajo.

\begin{tabular}{|c|c|c|c|c|c|c|c|c|c|c|c|c|c|c|c|c|c|c|}
\hline \multirow{2}{*}{ Horizonte } & \multicolumn{4}{|c|}{$\%$} & \multirow{2}{*}{ pH } & \multicolumn{6}{|c|}{$\mathrm{cmol}(+) / \mathrm{kg}$ suelo } & \multicolumn{2}{|c|}{$\%$} & \multicolumn{5}{|c|}{$\mathrm{mg} / \mathrm{kg}$ suelo } \\
\hline & $\mathbf{A}$ & $\mathbf{L}$ & Ar & MO & & $\mathbf{C a}$ & Mg & $\mathbf{K}$ & $\mathrm{Na}$ & CIC & CICE & SB & PSI & $\mathbf{P}$ & $\mathbf{S}$ & $\mathrm{Fe}$ & $\mathbf{C u}$ & B \\
\hline $2 \mathrm{AC}$ & 68 & 20 & 12 & 0.3 & 9.2 & 10.8 & 1.96 & 0.07 & 1.01 & 19.2 & 13.8 & 72.2 & 5.3 & 58 & 2 & N.D. & N.D. & 0.01 \\
\hline 3Btnss & 12 & 28 & 60 & 0,28 & 9,4 & 16,6 & 3,41 & 0,28 & 10,2 & 31,8 & 30,5 & 95,9 & 32,1 & 56 & 3 & N.D & 0,2 & 0,1 \\
\hline $5 B \operatorname{tn} 1$ & 10 & 28 & 62 & 0,04 & 9,0 & 21,5 & 2,89 & 0,31 & 6,7 & 43,9 & 31,4 & 71,5 & 15,3 & 69 & 18 & N.D & 0,3 & 0,3 \\
\hline $5 B \operatorname{tn} 2$ & 2 & 30 & 68 & 0,08 & 9,3 & 14,7 & 2,04 & 0,24 & 6,06 & 34,2 & 23,0 & 67,4 & 17,7 & 120 & 19 & 5 & 0,2 & 0,3 \\
\hline $7 \mathrm{Btn}$ & 4 & 24 & 72 & 0,04 & 9,0 & 21,1 & 2,66 & 0,31 & 12,8 & 40.0 & 36,9 & 92,3 & 32,0 & 60 & 16 & 4 & 0,2 & 0,2 \\
\hline
\end{tabular}

* A, L, Ar: Contenidos de arena, limo y arcilla, respectivamente. MO: contenido de materia orgánica. CIC: CIC medida a pH 7. CICE: CIC efectiva. SB: Saturación de bases. PSI: Porcentaje de sodio intercambiable. N.D.: No detectado.

$\mathrm{CICE}=(\mathrm{Ca}+\mathrm{Mg}+\mathrm{K}+\mathrm{Na}) \mathrm{SB}=[(\mathrm{Ca}+\mathrm{Mg}+\mathrm{K}+\mathrm{Na}) / \mathrm{CIC}] * 100 \mathrm{PSI}=(\mathrm{Na} / \mathrm{CIC}) * 100$

Tabla 4. Contenido mineralógico* (\%) de los horizontes argílicos de los paleosuelos de la secuencia superior en el área de trabajo.

\begin{tabular}{|c|c|c|c|c|c|c|c|c|c|}
\hline \multirow{2}{*}{ Horizonte } & \multicolumn{4}{|c|}{ Minerales de arcilla } & \multicolumn{5}{c|}{ Otros minerales } \\
\cline { 2 - 10 } & Illita-mica & I/S & Esmectita & Caolinita & Cuarzo & Fp & PI & Anatasa & Hematita \\
\hline 3Btnss & 3 & 4 & 19 & 17 & 50 & 1 & 3 & 1 & 1 \\
\hline $5 \mathrm{Btn} 1$ & 3 & 4 & 14 & 18 & 55 & 1 & 3 & 1 & 1 \\
\hline 5Btn2 & 3 & 2 & 11 & 18 & 59 & 1 & 3 & 1 & 1 \\
\hline 7Btn & 3 & 2 & 19 & 17 & 57 & 2 & 3 & 1 & 1 \\
\hline
\end{tabular}

* I/S: Intergrado Illita-Esmectita. Fp: Feldespato potásico. Pl: Plagiocla 
5Btn2 9.50 - $10.6 \mathrm{~m}$ (1.1 $\mathrm{m}$ de espesor); paleosuelo de color en húmedo 7.5YR6/4 (pardo claro); arcilloso; estructura en bloques subangulares medios, fuertes; plástico, ligeramente pegajoso; muchos argílanes continuos, prominentes; abundantes manchas de óxidos de hierro; pocas raíces finas y pocos poros finos; límites abruptos y planos.

6C $\quad 10.6$ - $11.98 \mathrm{~m}$ (1.38 $\mathrm{m}$ de espesor); capa de limolitas (textura limosa) de color en húmedo 5Y7/2 (gris claro); sin estructura (masiva); muy dura en seco; no plástica, ligeramente pegajosa; muchos poros finos; límites abruptos y planos.

7Btn 11.98 - $16.8 \mathrm{~m}$ (4.82 $\mathrm{m}$ de espesor); paleosuelo de color en húmedo 10YR5/8 (pardo amarillento); arcilloso; estructura en bloques subangulares medios, fuertes; plástico, no pegajoso; muchos argílanes continuos, prominentes; pocas raíces finas y pocos poros finos; presentes nódulos de hasta $5 \mathrm{~cm}$ de diámetro, de color 10YR7/2 (gris claro) y grietas verticales.

Los paleosuelos descritos en esta secuencia, excepto el horizonte $2 \mathrm{AC}$, son fuertemente arcillosos y muy fuertemente alcalinos, tienen muy bajo contenido de materia orgánica, alto contenido de bases y de fosforo, alta capacidad de intercambio catiónico; son deficientes en elementos menores y, exceptuando el $2 \mathrm{AC}$, son sódicos. Desde el punto de vista de su fertilidad natural pueden tener problemas serios debidos al Na.

El primer paleosuelo, identificado con el prefijo 2 en la nomenclatura de los horizontes, presenta muy poco desarrollo pedogenético $\mathrm{y}$, de todos los paleosuelos de esta secuencia, es el que presenta los menores contenidos de arcilla, de bases y de fosforo, así como la CIC más baja; además, es el que tiene el mayor contenido de materia orgánica y el único que no es sódico. Las características texturales pueden relacionarse con un material parental muy arenoso, y las químicas con una condición climática menos contrastante en cuanto a los contenidos de humedad entre la época de lluvias y la época seca. La mejora en las condiciones de humedad favoreció un incremento en la producción de biomasa vegetal y en la humificación de ésta, aunque siguió dominando la mineralización. Es de esperarse que el incremento en la humedad disponible del suelo no haya sido muy alto, puesto que no se presentó lixiviación importante de bases, ya que el pH se encuentra en los valores de los demás paleosuelos.

La disminución en la estacionalidad del clima la soporta el hecho de que en este suelo no se hayan dado procesos de iluviación de arcilla que hubieran generado argílanes. También es importante llamar la atención acerca de que es el único paleosuelo, de todos los identificados, que presenta rasgos de horizonte $\mathrm{A}$, lo que implica que la erosión se vio bastante menguada durante su formación, posiblemente por la congruencia de un clima con condiciones de humedad más homogéneas todo el tiempo y una cobertura vegetal más densa que pudo protegerlo. El bajo desarrollo de este suelo, y sobre todo la poca pérdida de bases en un suelo con una textura tan gruesa, que favorece el drenaje, también está mostrando que él estuvo expuesto a las condiciones ambientales durante un periodo muy corto y la pedogénesis no tuvo suficiente tiempo para actuar.

El horizonte 3Btnss, el más complejo de todos los observados, presenta evidencias obvias de cambio en el material parental, con respecto al suelo anterior. De todos los suelos arcillosos de esta secuencia es el que presenta un mayor con-

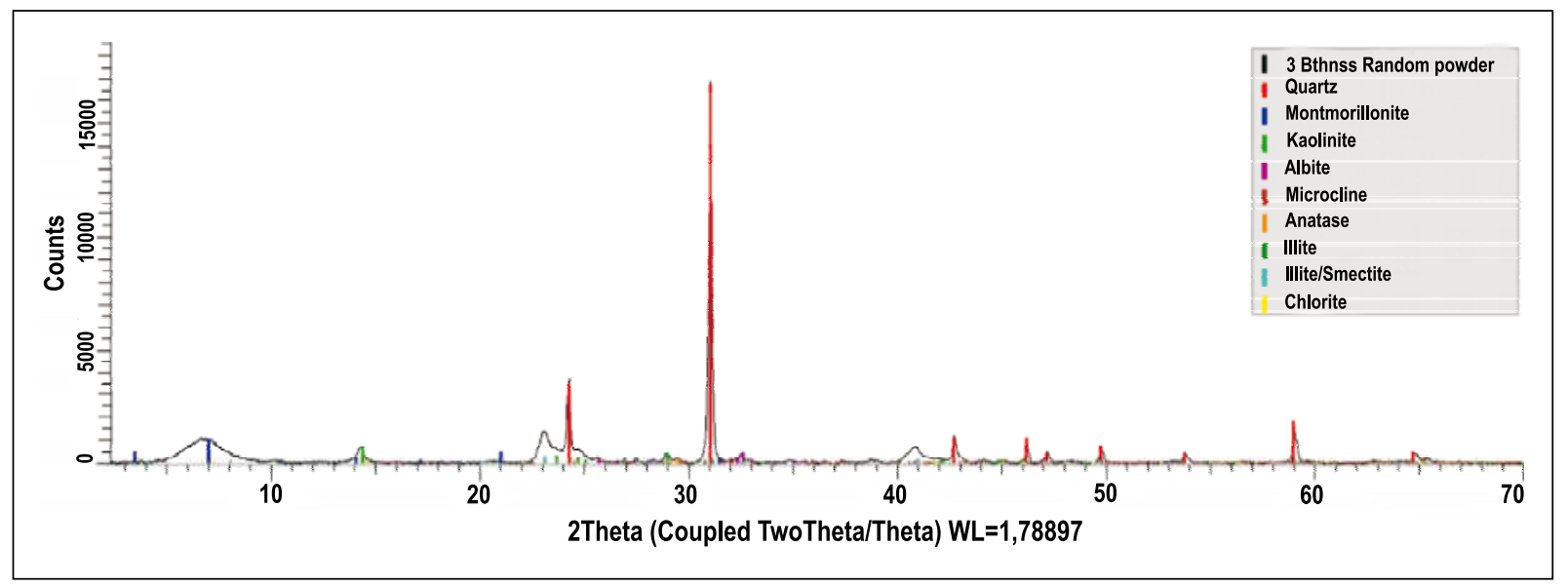

Figura 3. Difractograma de minerales y arcillas presentes en el 3BTnss, uno de los paleosuelos de la secuencia superior en el desierto de La Tatacoa. 
tenido de materia orgánica, a pesar de no ser un horizonte A. Sus características hacen suponer que durante su formación se presentaron condiciones estacionales y variables de clima que generaron varias pedogénesis sobre el mismo material:

- Es el horizonte que tiene el mayor contenido de $\mathrm{Mg}$, $\mathrm{y}$ un alto contenido de $\mathrm{Na}$ que pudieron incidir en la formación y/o preservación de las altas cantidades de montmorillonita presentes. Además, esta condición favorece la dispersión de los coloides necesaria para su iluviación y formación de los argílanes.

- Los altos contenidos de bases y la presencia de argílanes, slickensides y grietas indican un clima fuertemente estacional y contrastante en humedad, aunque sin excesos de ella pues no se presentó lixiviación de bases: es el horizonte con mayor $\mathrm{pH}$.

- $\mathrm{Al}$ interior del suelo, en profundidad se pudieron haber presentado condiciones de mal drenaje $\mathrm{y} / \mathrm{o}$ de fuertes fluctuaciones en el nivel freático favorecidas, probablemente, por la gran cantidad de arcilla y por la expansividad de ésta, que generaron las condiciones de óxidoreducción necesarias para la formación de los nódulos presentes.

- El clima, a pesar de su estacionalidad, permitió el desarrollo de una cobertura vegetal que aportó suficiente cantidad de materia orgánica para que se humificara y se translocara hacia el interior del suelo, movimiento que también se favorece por las condiciones estacionales del clima.

- Debió haberse presentado un cambio ambiental drástico cuando este suelo ya estaba en su madurez que fue capaz de decapitarlo. Pudo haber sido la llegada de una época de intensa sequía regional que erosionó el horizonte A, y posiblemente algo del B. Esto pudo haber estado acompañado de algún cambio local en el régimen hídrico de la cuenca que cambió la dinámica aluvial en ella y que explicaría el cambio en la granulometría al pasar de este horizonte al suelo suprayacente.

Los horizontes $5 \mathrm{Btn} 1$ y $5 \mathrm{Btn} 2$ son parte de un paleosuelo que debió haberse formado bajo unas condiciones climáticas muy secas y contrastadas. En ellos se encuentra la menor saturación de bases y de sodio, lo que puede estar relacionado, más que con una mayor lixiviación en él, con respecto a los otros paleosuelos de esta secuencia, con pequeñas diferencias en el material parental. Presentan un contenido muy bajo de materia orgánica que sugiere una alta mineralización de la poca biomasa que se produjo, y ninguna translocación de humus hasta ellos. La poca cantidad de materia orgánica también puede indicar que estos horizontes eran la parte más profunda de un suelo bastante espeso, que estuvo sometido a una erosión muy intensa y/o durante un largo tiempo que removió todo el horizonte A y buena parte del $\mathrm{B}$, dejando sólo aquella pequeña parte más interna del mismo, que es la menos afectada por la pedogénesis. También aquí se presentó cambio en el régimen hídrico de la cuenca que cambió la dinámica pedogenética por una de sedimentación continua de materiales limosos.

El horizonte 7Btn es bastante similar a los dos horizontes anteriores en sus propiedades, aunque con un espesor mucho mayor y con evidencias de la acción de procesos de vertisolización (grietas). Llama la atención el espesor del suelo preservado (no se sabe cuánto suelo se erosionó) que implica un periodo muy largo de estabilidad geomorfológica bajo un clima muy contrastado y seco. Entre este suelo y el descrito antes también se presentó un cambio en la dinámica hidrológica de la cuenca que promovió la sedimentación continua de limo. En éste, como en los dos suelos anteriores se presentó una importante acumulación de bases, posiblemente residual, y un proceso intenso de alcalinización que produjo los horizontes sódicos.

De acuerdo con las propiedades mostradas por los paleosuelos anteriores, ellos pueden clasificarse en el sistema taxonómico norteamericano (SSS, 2010) como se detalla a continuación:

El suelo $2 \mathrm{AC}-2 \mathrm{C} 1-2 \mathrm{C} 2-2 \mathrm{C} 3-2 \mathrm{C} 4$ no presenta horizonte diagnóstico subsuperficial y sólo tiene epipedón ócrico. $\mathrm{Su}$ régimen de humedad es ústico y el de temperatura isohipertérmico. Con estas características y su textura gruesa, el suelo clasifica como Ustic Torripsamment.

El horizonte 3Btnss representa un suelo con horizonte diagnóstico nátrico y con propiedades vérticas. El régimen de humedad corresponde al arídico y el de temperatura al isohipertérmico. El suelo corresponde a un Vertisol árido y sódico que, al nivel de subgrupo se nombra como Sodic Haplotorrert.

Los horizontes $5 \mathrm{~B}$ tn 1 y $5 \mathrm{Btn} 2$ son nátricos y el suelo tiene régimen de humedad arídico y de temperatura isohipertérmico, clasificándose como un Typic Natrargid.

El suelo del paleosuelo 7Btn es bastante similar al anterior, del cual se diferencia por la presencia de propiedades vérticas, las que llevan a clasificarlo como Vertic Natrargid.

\section{Paleosuelos en la Secuencia Inferior ("Lower Red Bed" de Fields y Henao, 1949)}

Como lo describieron Fields y Henao (1949), las capas rojas superior e inferior están separadas por unos $45 \mathrm{~m}$ de estratos 
de areniscas y limonitas de color gris y gris oliva, intercaladas con algunas capas de lodolitas pardas. Las capas de esta secuencia no presentan evidencias de pedogénesis y varían ligeramente en el color desde $5 \mathrm{Y} 7 / 2$ a $5 \mathrm{Y} 7 / 3$ (gris claro a amarillo pálido). La secuencia de paleosuelos inferior se desarrolló sobre lodolitas y presenta color rojo ladrillo en su parte media que gradan en su parte inferior y superior a colores grises, y que tienen 14,5 $\mathrm{m}$ de espesor.

En campo se observó que esta secuencia presenta un techo ondulado que corresponde a un antiguo paisaje colinado de poca elevación y que está sepultado por estratos grises, marcando una paleosuperficie y una discordancia leve. Esta secuencia incluye tres fragmentos de paleosuelos que se nombran, del techo a la base, como 10Bt, 12Btss y $14 \mathrm{Bt}$, cuyos espesores son $4.90 \mathrm{~m}, 3.90 \mathrm{~m}$ y $1.80 \mathrm{~m}$, respectivamente. La característica más sobresaliente de estos es la coloración roja marcada por los colores pardo rojizo y pardo rojizo oscuro, mucho más intensa que la que presentan los paleosuelos de la Secuencia Superior (Foto 2). En las Tablas 5 y 6, y en la Figura 4 se presentan los resultados de los análisis químicos y mineralógicos realizados a los paleosuelos de esta secuencia, y a continuación se hace la descripción de ella, en términos pedológicos.

10Bt 65.9 - $70.8 \mathrm{~m}$ (4.90 $\mathrm{m}$ de espesor); color en húmedo 5YR4/4 (pardo rojizo); franco arcillo limoso; estructura en bloques subangulares medios, débiles; friable, ligeramente plástico, no pegajoso; muchos argílanes continuos, prominentes; pocas raíces finas y pocos poros finos; comunes nódulos cilíndricos de hasta 5 $\mathrm{cm}$ de diámetro mayor y de color 10YR7/2 (gris claro); límite abrupto y plano.

11C1 70.8 - $89.2 \mathrm{~m}$ (18.4 m de espesor); capa de limolita (textura limosa) con color en húmedo $5 \mathrm{Y} 7 / 2$ (gris claro); sin estructura (masiva); muy dura en seco, no plástica, ligeramente pegajosa; muchos poros finos; límites abruptos y planos.

11C2 89.2 - $91.5 \mathrm{~m}$ (2.3 $\mathrm{m}$ de espesor); capa de limolita (textura limosa) con color en húmedo 5Y7/3 (amarillo pálido); sin estructura (masiva); muy dura en seco, no plástica, ligeramente pegajosa; muchos poros finos; límites abruptos y planos.

12Btss 91.6 - $95.5 \mathrm{~m}$ (3.90 $\mathrm{m}$ de espesor); color en húmedo 2.5YR3/4 (pardo rojizo oscuro); arcilloso; estructura en bloques subangulares medios y gruesos, moderados; firme en seco, ligeramente plástico, no pegajoso; muchos argílanes continuos, prominentes; pocas raíces y pocos poros finos; el horizonte contiene fragmentos milimétricos de carbón; están presentes slic- kensides estriados, bien definidos, grietas verticales y manchas de óxidos de hierro; límites abruptos y planos.

13C $95.5-96.5 \mathrm{~m}$ (1.00 m de espesor); capa de limolita de color en húmedo 5Y7/3 (amarillo pálido); limosa; sin estructura (masiva); muy dura en seco, no plástica, ligeramente pegajosa; muchos poros finos; límites abruptos y planos.

14Bt 96.5 - $98.3 \mathrm{~m}$ (1.80 $\mathrm{m}$ de espesor); color en húmedo 5YR5/4 (pardo rojizo); arcilloso; estructura en bloques subangulares medios y gruesos, fuertes; duro en seco, ligeramente plástico, no pegajoso; muchos argílanes continuos, prominentes grietas verticales; comunes raíces y poros finos; límites abruptos y planos.

15C $\quad 98.3-99.4 \mathrm{~m}$ (1.10 $\mathrm{m}$ de espesor); capa de limolita de color en húmedo $5 \mathrm{Y} 7 / 2$ (gris claro); limosa; sin estructura (masiva); muy dura en seco, no plástica, ligeramente pegajosa; muchos poros finos; límite abrupto y plano.

Los paleosuelos de esta secuencia son de textura pesada, fuerte a muy fuertemente alcalinos, presentan muy bajos contenidos de materia orgánica y altos en bases y en P; tienen alta saturación con $\mathrm{Na}$ y son deficientes en elementos menores. Tienen alta capacidad de intercambio catiónico. En los minerales de arcilla predominan la caolinita y las esméctitas, casi en proporciones iguales. Presentan, en general, un buen nivel de fertilidad natural.

El horizonte 10Bt presenta un gran espesor que implica un periodo largo de estabilidad geomorfológica en la zona. Los argílanes que posee indican la presencia de un clima fuertemente estacional y contrastado, y los nódulos, condiciones de óxido-reducción, probablemente debidas a fluctuaciones en el nivel freático y a dificultades en la percolación profunda por la presencia de los cutánes, ya que su textura no es pesada. Tiene un contenido de materia orgánica que puede implicar una pequeña mejora en las condiciones hídricas de la zona durante su formación que permitió el establecimiento de una cobertura vegetal más densa, con mayor producción y humificación de materia orgánica, así como su movilización hacia el interior del suelo. La presencia de un horizonte argílico espeso, bien desarrollado y con alta saturación de bases, el régimen de humedad ústico y de temperatura isohipertérmico hacen que este suelo se clasifique como Typic Paleustalf.

El horizonte 12Btss también tiene un espesor considerable que debió adquirirse bajo una gran estabilidad geomorfológica en la zona. La presencia de argílanes y de propiedades 
vérticas refleja un clima estacional contrastado, y el poco contenido de materia orgánica se relaciona con una condición climática más seca que la del paleosuelo anterior. El régimen de humedad de este suelo debió ser arídico y el de temperatura, isohipertérmico; presenta un horizonte argílico bien desarrollado, con alta saturación de bases, y propiedades vérticas que hacen que se clasifique como Typic Haplotorrert.

El último paleosuelo identificado, con un horizonte 14Bt es, químicamente, muy similar al anterior (Tabla 5). Presenta un incremento significativo en el contenido de materia orgánica, con respecto a su antecesor, que puede relacionarse con un pequeño incremento en el suministro de humedad que promovió una mayor producción de biomasa vegetal y una humificación un poco mayor que mejoró la acumulación de ella en el suelo. La mejora climática pudo cambiar el régimen de humedad hasta ústico. El régimen de temperatura sigue siendo isohipertérmico. El horizonte argílico bien desarrollado y con saturación de bases alta, junto con los regímenes climáticos anotados y las propiedades vérticas observadas, hacen que este suelo se clasifique como Torrertic Haplustalf.

Tabla 5. Propiedades* químicas de los paleosuelos de la secuencia inferior en el área de trabajo.

\begin{tabular}{|c|c|c|c|c|c|c|c|c|c|c|c|c|c|c|c|c|c|c|}
\hline \multirow{2}{*}{ Horizonte } & \multicolumn{4}{|c|}{$\%$} & \multirow{2}{*}{ pH } & \multicolumn{6}{|c|}{$\operatorname{cmol}(+) / \mathrm{kg}$ suelo } & \multicolumn{2}{|c|}{$\%$} & \multicolumn{5}{|c|}{$\mathrm{mg} / \mathrm{kg}$ suelo } \\
\hline & $\mathbf{A}$ & $\mathbf{L}$ & Ar & MO & & $\mathbf{C a}$ & Mg & $\mathbf{K}$ & $\mathbf{N a}$ & CIC & CICE & SB & PSI & $\mathbf{P}$ & $\mathbf{S}$ & $\mathbf{F e}$ & $\mathbf{C u}$ & $\mathbf{B}$ \\
\hline $10 \mathrm{Bt}$ & 18 & 46 & 36 & 0,22 & 9,0 & 17,0 & 3,75 & 0,21 & 3,98 & 32,2 & 24,9 & 77,55 & 12,38 & 112 & 3 & 2 & 0,3 & 0,6 \\
\hline 12Btss & 4 & 28 & 68 & 0,04 & 9,1 & 25,7 & 2,14 & 0,31 & 4,75 & 34,8 & 32,9 & 94.54 & 13,65 & 113 & 4 & 1 & 0,2 & 0,4 \\
\hline $14 \mathrm{Bt}$ & 6 & 32 & 62 & 0,22 & 8,9 & 27,9 & 2,36 & 0,34 & 4,16 & 34,3 & 34,8 & 101,2 & 12,11 & 105 & 46 & 1 & 0,1 & 1,0 \\
\hline
\end{tabular}

A, L, Ar: Contenidos de arena, limo y arcilla, respectivamente. MO: contenido de materia orgánica. CIC: CIC medida a pH 7. CICE: CIC efectiva. SB: Saturación de bases. PSI: Porcentaje de sodio intercambiable.

$\mathrm{CICE}=(\mathrm{Ca}+\mathrm{Mg}+\mathrm{K}+\mathrm{Na}) \mathrm{SB}=[(\mathrm{Ca}+\mathrm{Mg}+\mathrm{K}+\mathrm{Na}) / \mathrm{CIC}] * 100 \mathrm{PSI}=(\mathrm{Na} / \mathrm{CIC}) * 100$

Tabla 6. Contenido mineralógico* (\%) de los horizontes argílicos de los paleosuelos de la secuencia inferior en el área de trabajo.

\begin{tabular}{|c|c|c|c|c|c|c|c|c|c|}
\hline \multirow{2}{*}{ Hotrizonte } & \multicolumn{4}{|c|}{ Minerales de arcilla } & \multicolumn{5}{c|}{ Otros minerales } \\
\cline { 2 - 10 } & Illita-mica & I/S & Esmectita & Caolinita & Cuarzo & Fp & PI & Anatasa & Hematita \\
\hline $10 \mathrm{Bt}$ & 2 & 2 & 14 & 11 & 64 & 2 & 3 & 1 & 1 \\
\hline $12 \mathrm{Btss}$ & 3 & 3 & 13 & 19 & 56 & 1 & 2 & 1 & 1 \\
\hline $14 \mathrm{Bt}$ & 3 & 2 & 12 & 16 & 61 & 1 & 3 & 1 & 1 \\
\hline
\end{tabular}

* I/S: Intergrado Illita-Esmectita. Fp: Feldespato potásico. Pl: Plagioclasa.

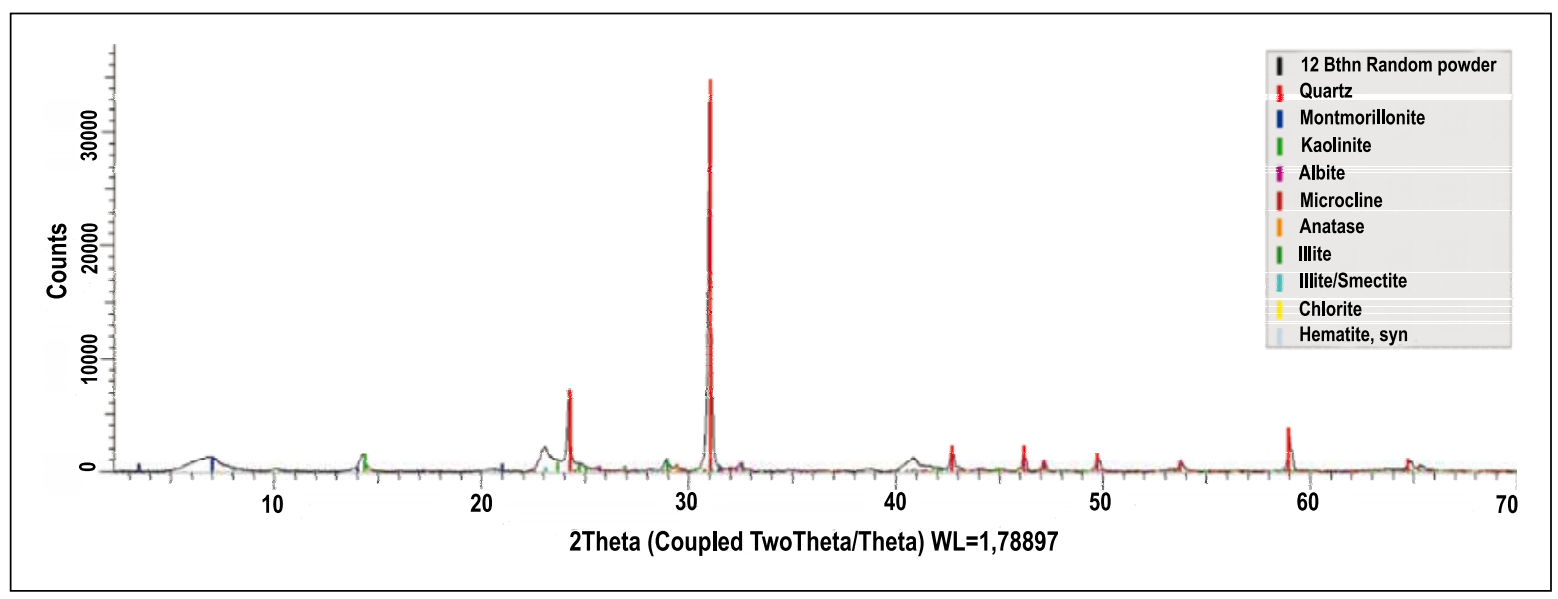

Figura 4. Difractograma de minerales y arcillas presentes en el 12BTss, uno de los paleosuelos de la secuencia inferior en el desierto de La Tatacoa. 


\section{Síntesis}

A manera de síntesis se pueden destacar los siguientes aspectos pedogenéticos en los paleosuelos observados, Foto 2 exceptuando el correspondiente al perfil $2 \mathrm{AC}-2 \mathrm{C}$ :

- Todos los fragmentos de paleosuelos se desarrollaron de materiales parentales arcillosos o, por lo menos, de materiales que produjeron grandes cantidades de arcilla por meteorización y pedogénesis.

- El clima dominante en la evolución de estos suelos corresponde a uno seco y muy contrastado en humedad.
- Todos los fragmentos de paleosuelos están separados entre sí por capas de arena o de limo que implican alteraciones en el comportamiento hídrico en la cuenca y, por ende, en la dinámica sedimentaria en el sitio. Estas alteraciones pueden originarse por cambios climáticos regionales o por cambios en el nivel de base de la cuenca y también pueden ser responsables, por lo menos en parte, de la intensa erosión que se ha dado en la zona durante todo el tiempo.

- Todos los fragmentos de paleosuelos presentan horizontes argílicos; éstos requieren, para su formación,

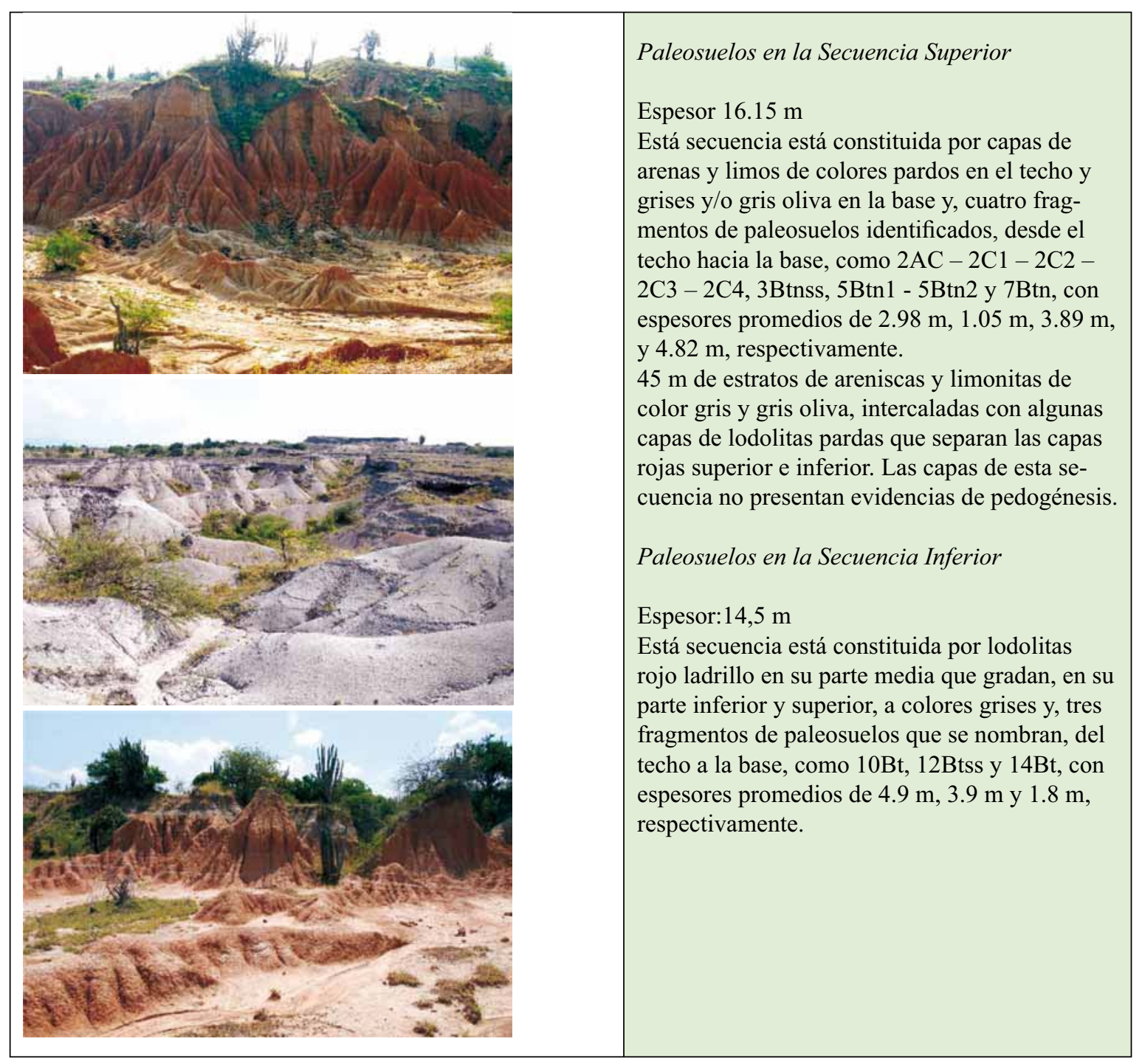

Foto 2. Registro fotográfico de las secuencias que contienen los paleosuelos del Terciario localizados en la vereda El Cuzco, sector El Observatorio, desierto de la Tatacoa, Huila, Colombia. 
contrastes de humedad, estabilidad geomorfológica y condiciones de dispersión de coloides, necesaria para su movilización y precipitación dentro del suelo (Pulido et al., 1990; Malagón et al., 1995; Buol et al., 1997 y SSS, 1999).

- El comentario anterior, unido al espesor que se consigue sumando todos los horizontes argílicos descritos (20.36 $\mathrm{m})$, implica que se necesitaron miles de años para tener las secuencias de paleosuelos analizadas y otros suelos y otros materiales que se perdieron por erosión y que no se pueden cuantificar en la actualidad.

- En todos los fragmentos de paleosuelos se presentó una fuerte erosión que los decapitó a todos, eliminando los horizontes A, y seguramente otros horizontes subsuperficiales transicionales y los horizontes $\mathrm{B}$.

- La abundante cantidad de cuarzo en los suelos, la escasez de feldespatos y otros minerales meteorizables, y la abundancia en esméctitas y caolinita indican una meteorización intensa del material parental en un ambiente oxidante.

- Los procesos pedogenéticos dominantes en los paleosuelos han sido: mineralización de la materia orgánica, rubefacción, braunificación o pardificación generalizada en el suelo por acumulación de Fe oxidado, con o sin materia orgánica, argiluviación y lessivaje de arcilla, fersialitización que conlleva a la formación de las esméctitas, alcalinización (acumulación de $\mathrm{Na}$ intercambiable), adensamiento (endurecimiento), vertisolización o argiloturbación y erosión hídrica. Los suelos presentan un enriquecimiento residual de bases y de $\mathrm{P}$ que, en términos de procesos pedogenéticos, podría definirse como eutrofización. Estos procesos entrañan, por una parte, modificaciones en la mineralogía detrítica, y por otra, neoformación de especies arcillosas:

a. Destrucción de micas y feldespatos, que son reemplazados por arcillas, y corrosión de granos de cuarzo por el plasma arcilloso. Esto implica que el sedimento perdió gran parte de su carácter arcósico después de su depositación. Las arcillas que se generan como consecuencia de esta alteración son esmectitas, las cuales no aparecen en los minerales detríticos, posiblemente debido a que se haya producido una desestabilización, por envejecimiento, de las esméctitas previas, dando como resultado una illitización generalizada.

b. Rubefacción, con filiación de hematites, que afecta principalmente a las granulometrías más finas. En estas partes más finas se impregna todo el plasma, haciéndose opaco en muchas ocasiones, mientras que en las gruesas afecta sólo al cemento o matriz arcillosa marcando, especialmente, las granoestriaciones. Por lo general, disminuye de techo a base en las secuencias y no afecta tanto a las partes más bajas de éstas, lo cual es una evidencia de que esta rubefacción está asociada también a la actividad paleoedáfica. La fuente del $\mathrm{Fe}$, muy posiblemente, sea la desestabilización de las biotitas y de las cloritas que no han desaparecido por completo en la actualidad.

c. Carbonatación incipiente. En varios casos pueden observarse las distintas zonas del perfil de una costra, desde una incipiente nodulización hasta una costra laminar muy delgada.

d. Durante el periodo de menor drenaje se produce la formación de esmectitas, probablemente a partir de la alteración de piroxenos y olivinos (Craigh y Loughnan, 1964 y Loughnan, 1969). Posteriormente, con el aumento del drenaje, el suelo pierde los cationes básicos solubles y aumenta la actividad del $\mathrm{Al}$, lo que provoca una progresiva aluminización de los minerales esmectíticos y la formación de caolinita a través del interestratificado illita-esmectita. La llegada de arenas intercaladas con limolitas protege el suelo original de los agentes de alteración y explica que se mantenga todavía en la actualidad el interestratificado illita-esmectita.

- El aporte detrítico de la cuenca presenta una alta monotonía en todo el conjunto como un sedimento claramente inmaduro, con abundante cuarzo y siliciclastos. Esto hace que la composición mineralógica en todos los paleosuelos sea bastante similar, cambiando sólo la cantidad y su estado de alteración. Los minerales más comunes son cuarzo $(>50 \%)$, montmorillonita (esmectita) (19\%), caolinita (18\%), albita, microclina, anatasa, illita, integrados illita/esmectita, clorita y hematita. En general, los minerales se encuentran altamente meteorizados, algunos recubiertos de óxidos de hierro y agregados lechosos.

\section{Conclusiones}

En las "capas rojas" de Fields (1959), se pueden reconocer hasta siete fragmentos de paleosuelos, localizados dentro de dos secuencias sedimentarias, una superior con cuatro paleosuelos y una inferior con tres, en ambos casos formados en el Mioceno, bajo climas desde contrastados en humedad, hasta áridos y en paleorelieves colinados de baja altitud. Es- 
tos paisajes terrestres y sus suelos portadores de biomas secos debieron coexistir con planicies aluviales pobladas por biomas boscosos dependientes en gran medida de la mayor humedad del sedimento y de los aportes de agua de desborde de grandes ríos.

La Secuencia Superior tiene un espesor de $16.15 \mathrm{~m}$ y está constituida por cuatro fragmentos de paleosuelos identificados, desde el techo hacia la base, como $2 \mathrm{AC}-2 \mathrm{C} 1-2 \mathrm{C} 2$ - 2C3 - 2C4, 3Btnss, 5Btn1 - 5Btn2 y 7Btn. El 3Btnss, el más complejo, presenta diferencias en el material parental con el paleosuelo anterior y mayor contenido de materia orgánica, y sus características hacen suponer que durante su formación se presentaron condiciones estacionales y variables de clima que generaron varias pedogénesis sobre el mismo material. Los 5Btn1 y 5Btn2 debieron haberse formado bajo unas condiciones climáticas muy secas y contrastadas $\mathrm{y}$ bajo un régimen hídrico de la cuenca que cambió la dinámica pedogenética por una de sedimentación continua de materiales limosos. El 7Btn es muy similar a los dos anteriores, aunque con un espesor mucho mayor y con evidencias de la acción de procesos de vertisolización, caracterizando un periodo muy largo de estabilidad geomorfológica bajo un clima muy contrastado y seco. Estos paleosuelos se han clasificado como Ustic Torripsamment, el 2AC - 2C, Sodic Haplotorrert el 3Btnss, Typic Natrargid el 5Btn y como Vertic Natrargid el 7Btn.

La Secuencia Inferior tiene un espesor de 14,5 m e incluye tres fragmentos de paleosuelos identificados, desde el techo hacia la base, como $10 \mathrm{Bt}, 12 \mathrm{Btss}$ y $14 \mathrm{Bt}$. La característica más sobresaliente de estos paleosuelos es la coloración roja marcada por los colores pardo rojizo y pardo rojizo oscuro, mucho más intensa que la que presentan los paleosuelos de la Secuencia Superior. El 10Bt, de gran espesor, evidencia un periodo largo de estabilidad geomorfológica en la zona y un mejoramiento en las condiciones hídricas. El 12Btss, también de un espesor considerable, refleja un clima estacional contrastado, y el poco contenido de materia orgánica sugiere una condición climática más seca que la del paleosuelo anterior. El 14Bt presenta un incremento significativo en el contenido de materia orgánica, que puede relacionarse con un pequeño incremento en la humedad. Estos suelos se han clasificado como Typic Paleustalf el 10Bt, Typic Haplotorrert el 12Btss y Torrertic Haplustalf el 14Bt.

\section{Agradecimientos}

Este proyecto recibió aportes económicos de la Fundación Leakey, de la Facultad de Ciencias de la Universidad Nacional de Colombia, Sede Medellín, de la Facultad de Ingeniería de la Universidad de Antioquia y del Laboratorio GMAS(+).
Se agradece al Señor Jorge Arcila, su valioso acompañamiento durante el trabajo de campo.

\section{Referencias}

Altschuler, Z. S., Schnepfe, M. M., Silber, C. C., and Simon, F. O. 1983. Sulfur diagenesis in Everglades's peat and the origin of pyrite in coal. Science, v. 221, p.221-227.

Buol, S. W.; Hole, F. D.; Mccracken, R. J. and Southard, R. J. 1997. Soil genesis and classification. Fourth edition. Iowa State University Press. USA. 527 p.

Bryan, W. H., Teakle, L. J. H. (1949). Pedogenic inertia - a concept in soil science. Nature 164, P969.

Catt, J. A., 1991. Paleopedology manual Quaternary International. INQUA. Pergamon Press.

Craig, D. C. Y Loughnan, F. C. 1964. Weathering of basic volcanic rocks. Australian Journal of Soil Science 2(2):218-234.

Fields, R.W Y Henao. 1949. Honda formation of the upper Magdalena river basin, Colombia, S.A. [abs.]: Geological Society of America Bulletin, v. 60, p. 1894.

Fields, R.W. 1959. Geology of the La Venta Badlands Colombia, South America. U. California, Publ. Geol. Scienc., 32(6):405-444. California.

Instituto de Investigaciones Geológico-Mineras (INGEOMINAS). 2002. Geología de la plancha 303 Colombia departamentos de Huila, y Tolima. Metaescala 1:100.000 memoria explicativa. Septiembre de 2002.

Fernández M., Armenteros I. y Blanco J. A. 1988. Procesos de alteración y paleosuelos ligados a la sedimentación miocena del NE. de Segovia, depresión del Duero. Acta Geológica Hispánica, v. 23 (1988), págs. 269-281.

Gey, M. P. y Garcia, C. 1993. Caracterización de un paleosuelo enterrado bajo los sedimentos terciarios de As Pontes de García Rodríguez. (A Coruña, Galicia, NW España). Cuaderno Lab. Xeolóxico de Laxe Coruña. 1993. Vol. 18, pp. 325-335.

González, L. H.; Parra, L. N. y Flórez, M. T. 1993. Andisoles fósiles en el Norte de Colombia. Suelos Ecuatoriales 23(1-2): 31-44.

Guerrero, J. 1991. Magnetostratigraphy of the upper part of the Honda Group and Neiva Formation. Miocene Uplift of the Colombian Andes. Tesis PhD, Duke Univ., 108 p.

Guerrero, J. 1994. Stratigraphy and sedimentary environments of the Honda Group in the La Venta area. Miocene uplift of the Colombian Andes. En: Kay, R.; Madden,R. H.; Cifelli, R. L.; Flynn, J. J. (Eds). A history of Neotropical Fauna: Vertebrate Paleobiology of the Miocene of Tropical South America. Washington.

Kraus Mary J. 1999. Paleosols in clastic sedimentary rocks: their geologic applications. Earth Science Reviews 47 Ž1999. 41-70.

Loughnan, F. C. 1969. Chemical Weathering of the Silicate Minerals. American Elsevier Publ. Comp. Inc., New York 1969. 154 Seiten, 62 Abbildungen. Dfl. 43.50

Malagón, D.; Pulido, C.; Llinás, R. D.; Chamorro, C. y Fernández, J. 1995. Suelos de Colombia. Origen, evolución, clasificación, distribución y uso. Instituto Geográfico Agustín Codazzi (IGAC). Santafé de Bogotá. 632 p.

Mantilla G., et al. 2011. Los suelos: estabilidad, producción y degradación. En: http://issuu.com/olneyivanescobarforero/docs/7649

Morrison, R. 1978. Quaternary Soil Stratigraphy. Concepts, Methods, and Problems. En: Cuaternary soil. Third York Quaternary Simposium. Geo Abstracts, Norwich, England. 
Nettleton, W.D.; Olson, C.G.; Wysocki, D.A. 2000. Paleosol classification: Problems and solutions. Catena 41: 61-92.

Potenciano A., Espejop R. y Garzon G. 1997. Geogaceta, 22. 157-160.

Pulido, C.; Malagón, D. y Llinás, R. 1990. Paleosuelos del piso alto andino en la región montañosa circundante a Bogotá. Investigaciones. V. 2, No 2. Instituto Geográfico Agustín Codazzi (IGAC). Bogotá. $198 \mathrm{p}$.

Retallack, G. J. 1988. Field recognition of Paleosols. Geological Society of America, Special Paper 216, 20pp.

Retallack, G. J. 1990. Soils of the past. Unwin-Hyman, 510 p., Londres.

Retallack, G. J. 2001. Soils of the Past. An introduction to paleopedology, 2nd de Blackwell, USA, $391 \mathrm{pp}$.

Retallack, G. J. 2004. Late Oligocene bunch grassland and early Miocene sod grassland paleosols from central Oregon, USA. Palaegeography, Palaeoclimatology, Palaeoecology. 207, 203-237.

Retallack G. and Kirby M. X. 2007. Middle Miocene global change and paleogeography of Panama, palaios, v. 22, p. 667-679 Miscelanea.

Royo y Gómez, J. 1942. Contribución al conocimiento de la geología del Valle Superior del Magdalena, Departamento del Huila. CCEGOC, 5: 261-318. Bogotá.

Ruhe, R.V. 1965. Quternary paleopedology. En: The quternary of the United States. Ed:

Schwarz, T. 1997. Lateritic paleosols in central Germany and implications for Miocene paleoclimates: Palaeogeography, Palaeoclimatology, Palaeoecology. V. 129, p. 37-50.

Schoeneberger, P. J.; Wysocki, D. A.; Benham, E. C. and Broderson, W.D. 2002. Field book for describing and sampling soils. Version 2.0. Natural Resources Conservation Service. National Soil Survey Center. Lincoln, NE. USA.

Soil Survey Staff. 1999. Soil Taxonomy: A Basic System of Soil Classification for Making and Interpreting Soil Surveys. Second Edition. Agriculture Handbook Number 436. United States Department of Agriculture. Natural Resources Conservation Service. Washington, DC. $871 \mathrm{p}$.

Soil Survey Staff (SSS). 2010. Keys to Soil Taxonomy. Eleventh Edition. United States Department of Agriculture. Natural Resources Conservation Service. Washington, D.C. 338 p.
Stirton, R. A. 1953. Vertebrate paleontology and continental stratigraphy in Colombia. Geol. Soc. Am. Bull., 64: 603-622. New York.

Stille, H. 1907. Geologische studien im gebiete des río Magdalena. Festchr. Adolf V.Koenen. pp 227-358. Sttutgart.

Stille, H. 1938. Estudios geológicos en la región del rio Magdalena. Comp. Est. Geol. Ofic. Col., 4(1):125-182. Bogotá.

Takemura, K.; Danhara, T. 1986. Fission-track dating the upper part of MioceneHonda Group in La Venta Badlands, Colombia. Kyoto Univ., Overseas Research Reports of New World Monkeys, 5: 31-38. Kyoto.

Van Houten, F. B., Travis, R. B. 1958. Cenozoic deposits, Upper Magdalena Valley, Colombia. Am. Assoc. Petrol. Geol. Bull., 52: 675-702.

Villarroel, C.; Setoguchi, T.; Brieva, J.; Macía C. 1996. Geology of the La Tatacoa "Desert" (Huila, Colombia): Precisions on the Stratigraphy of the Honda Group, the Evolution of the "Pata High" and Presence of the La Venta Fauna. Mem. Fac. Sci., Kyoto Univ., Series Geol. and Mineral. 58 (1-2): 41-66. Kyoto.

Wellman, S. S. 1970. Stratigraphy and petrology of the nonmarine Honda Group (Miocene), Upper Magdalena Valley, Colombia. Geol. Soc. Am. Bull., 81(8):2353-2374. New York.

Universidad Surcolombiana, Universidad del Tolima, Universidad de Cundinamarca. 2001. Estudios de caracterización biofisica y socioeconómica de la Ecorregión estratégica de la Tatacoa y su área de influencia. Ibagué-Tolima. Eds. Ministerio de Medio Ambiente, Cormagdalena, Cortolima, Corporación Autónoma Regional del Alto Magdalena, $135 \mathrm{p}$.

Universidad Surcolombiana Facultad de Ingeniería (USCO). 2005. Convenio Interadministrativo No. 1071-200 de 2005, Gobernación del Huila- CAM-USCO.

Yaloon, D. H. 1971. Soil forming processes in time and space. En: Paleopedology: Origin, Nature and Dating of Paleosols. Yaloon, D.H., ed. Int. Soc. Soil Sci., Israel Univ. Press, Jerusalem, Israel, pp. 29-39.

Recibido: 10 de mayo de 2013

Aceptado para su publicación: 4 de junio de 2013 